\title{
Urdimento
}

\section{TRAGÉDIA GREGA E CENOGRAFIA: A ENCENACÃO DOS TEXTOS TRÁGICOS NA CENA BRASILEIRA PÓS-MODERNA}

\author{
Gilson Motta
}

\section{Resumo}

O texto aborda o movimento de revivificação da tragédia grega na cena brasileira, fazendo uma análise de diversas encenações contemporâneas. A análise privilegia o tema do espaço e da cenografia, de modo a refletir, de um lado, sobre a forma como ambos são determinantes para a criação do sentido do trágico e, de outro, sobre as características da cenografia brasileira no contexto do pós-modernismo.

Palavras-chave: tragédia grega, cenografia, encenação.

\begin{abstract}
The article approaches the movement of revival of Greek tragedy in Brazilian theatre and does an analysis of several contemporary theatrical productions. The analysis highlights the theme of space and stage design, to reflect on the one hand, on how both are essential to creating the sense of the tragic, and another on the characteristics of the Brazilian stage design in the post? modernism.
\end{abstract}

Keywords: greek tragedy, stage design, staging.

\section{Apresentação: Cenografia e tragédia grega}

O presente estudo vem apresentar os resultados parciais de minha pesquisa de Pós-Doutorado, realizada na Universidade Federal do Estado do Rio de Janeiro (UNIRIO) com orientação do Prof. Dr. José Dias. O objetivo da pesquisa é discutir o modo como o espaço e a cenografia contribuem para a construção da tragédia e do trágico no momento de revivificação da tragédia grega. Este momento, ocorrido na cena mundial no final da década de 1960 e consolidado nos anos 80, constitui-se numa das principais tendências do teatro pós-moderno.

Em Why Greek Tragedy in the Late Twentieth Century?, artigo que serve de Introdução à obra Dionysus Since 69, Edith Hall afirma que a encenação contemporânea retoma o texto grego a fim de questionar aspectos sociais,

${ }^{\mathrm{G} G i l s o n}$ Motta é Doutor em Filosofia, Cenógrafo, Diretor teatral e professor de Cenografia e História do Teatro na Universidade Federal de Ouro Preto. Atualmente, está concluindo pesquisa de Pós-Doutorado com o tema espaço e tragédia, onde analisa a cenografia das encenações brasileiras contemporâneas de tragédias gregas. 


\section{Urdimento}

políticos e estéticos da nossa sociedade. Partindo desta premissa, em minhas pesquisas venho buscando analisar esse processo de revivificação da tragédia grega na cena brasileira. Para os fins da pesquisa, estabeleci um recorte espacial que abarca apenas a produção apresentada nas cidades de São Paulo e Rio de Janeiro, enquanto principais pólos de cultura teatral do Brasil, e um recorte temporal feito a partir do ano de 1999. Considerando a importância do tema do espaço na arte contemporânea, a pesquisa enfoca, sobretudo, a Cenografia dos espetáculos em sua relação com o conceito de trágico e em seu diálogo com as teorias poéticas do Pós-Modernismo.

\section{A encenação da tragédia e a cenografia pós-moderna}

O surgimento da moderna encenação teatral insere a tragédia grega nos debates sobre o modernismo no teatro, levantando a questão da possibilidade de assimilação do texto antigo pelo espectador moderno. Embora a idéia de encenar os textos antigos pareça contradizer a disposição da arte moderna, a reinvenção da tragédia foi decisiva para a afirmação da arte da encenação e para a renovação do teatro, pois ao se lidar com o teatro em sua origem, a própria função do encenador se radicaliza, a saber, a função de interpretar a obra e criar um código teatral que a torne legível para o espectador atual. Talvez, devido a esta posição paradoxal e à polissemia do texto antigo, a tragédia tenha se afirmado como um teatro experimental, como observa Helene Foley em Modern Performance and Adaptation of Greek Tragedy. Essa atitude de experimentalismo estará presente em diversos espetáculos brasileiros, como veremos mais adiante.

No que diz respeito à linguagem da encenação, tal experimentalismo envolve duas atitudes dominantes, como nota Patrícia Legangneux, em Les tragédies grecques sur la scène moderne. Une utopie théâtrale: a acentuação ou a redução da distância cultural e histórica entre o texto antigo e a sociedade atual. Importa-nos aqui observar que estas duas atitudes também se fazem presentes na abordagem espacial. A cena moderna será marcada pela consciência radical da diferença entre o seu espaço de representação e o espaço grego. Esta diferença mostra-se no caráter não-representativo do espaço grego que, como puro espaço de jogo, não contém referências a um universo trágico. A tragicidade da cena é dada pela existência de zonas de tensões e de conflitos entre as diferentes áreas do espaço. A recriação destas zonas na cena moderna está condicionada à evolução da cenografia. Se, por um lado, a cenografia arquitetônica não-representativa é a principal inovação da cena moderna, por outro, o questionamento do edifício teatral tradicional forma a outra face do modernismo, conduzindo à criação de novas formas de espaços cênicos. Desta forma, os encenadores atuais dispõem de uma multiplicidade de espaços para a tragédia: o palco tradicional, os novos espaços cênicos e os

Tragédia grega e cenografica: a encenação dos textos trágicos... Gilson Motta. Dezembro 2008 - № 11 
espaços alternativos. Assim, numa vertente, a encenação da tragédia grega envolverá uma busca de novos lugares teatrais. Numa outra, com suas novas técnicas, tecnologias e materiais, a moderna estética cenográfica buscará criar um espaço trágico na caixa cênica tradicional. Em termos de linguagem cênica, a cenografia tanto pode indicar ou representar o mundo grego, quanto pode romper este referencial, criando um mundo cênico dotado de leis próprias. A cena pós-moderna irá fundir estas tendências.

$\mathrm{O}$ conceito de Pós-modernismo relaciona-se às manifestações culturais que surgiram no interior de um determinado contexto histórico, apontando para uma mudança profunda nas formas de produção e de recepção dos objetos culturais e artísticos. No que tange à arte teatral, o anúncio de uma ruptura com os ideais modernistas se configura com maior radicalismo a partir do final dos anos 60. Esta ruptura implica uma maior abertura do teatro ocidental para outras formas culturais de compreensão do fenômeno teatral. Esta consciência implica necessariamente a absorção e apropriação de novas matrizes imagéticas e estilísticas. Assim, é neste processo de re-elaboração do próprio conceito de teatralidade que se forma também um teatro de caráter polimorfo, como é o teatro do século XX. Neste movimento, um conceito cardinal como o de representação é reformulado e superado. A crise deste conceito está na raiz do teatro e da cenografia pós-modernos.

Assim, pensar a encenação do texto grego na atualidade é pensar na relação existente entre o passado, a tradição, as origens do teatro ocidental e todas as formas de ruptura estabelecidas pela própria cultura pós-moderna. Este pensar implica um mover-se num terreno de contradições e dicotomias: entre o passado e a sua negação, o primitivo e o novo, o texto-palavra e as novas tecnologias da imagem, a alta cultura e a cultura popular, a representação e a ruptura com as formas de representação, a arte e a antiarte, entre outros. Sendo o texto grego aquele mesmo que vem estabelecer uma referência de origem da cultura teatral ocidental, ele termina por ser também o tex to que mais propicia uma acentuação destas contradições. Desta forma, pergunta-se aqui como esta poética tradicional da tragédia e os temas que lhe são peculiares se coadunam com os ideais e as práticas artísticas e culturais da pós-modernidade? Como isso se revela na Cenografia?

Segundo autores como Teixeira Coelho e Steven Connor, as teorias de Antonin Artaud constituem a base para a afirmação de uma estética pós-moderna: elas anunciam uma valorização da obra-como-processo, em detrimento do fechamento e acabamento da obra; elas valorizam a idéia da presentação, em detrimento da representação; elas afirmam a multiplicidade de eventos visuais e auditivos, isto é, a proliferação e a superposição de signos em contradição; elas dissolvem a idéia da obra de arte unificada; elas rompem com

Dezembro 2008 - N $11 \quad$ Tragédia grega e cenografica: a encenação dos textos trágicos... Gilson Motta. 


\section{Urdimento}

o princípio da identidade, tornando relativo o sentido da obra, o que implica uma valorização da singularidade dos receptores e o papel decisivo que estes exercem na construção do sentido da obra. Ora, segundo Arnold Aronson, a cenografia também parece repercutir tais teorias. Segundo o autor, durante as décadas de 70 e 80 , desenvolveu-se um estilo cenográfico fundamentalmente diferente na abordagem e nos valores estéticos, estilo este que questiona as formas herdadas durante o período modernista. O princípio conceitual desta cenografia encontra-se na idéia da ruptura com a "unidade orgânica" da cena. "Uma espécie de visão pan-histórica e oniestilística passou a dominar a cenografia; o mundo é visto como uma multiplicidade de elementos e imagens díspares, muitas vezes incongruentes e conflitantes, e a cenografia reflete esta perspectiva” (ARONSON, 1992: 9). A partir deste princípio, o autor identifica alguns traços marcantes da cenografia pós-moderna: a) a ausência de um foco narrativo único: presença da descontinuidade, da ruptura; b) a ênfase na relação entre o espectador e o objeto; c) a ausência consciente de unidade entre os elementos visuais da produção, rompendo com a sinergia estética moderna; d) a sobreposição e mistura de estilos; d) a afirmação da presença do passado, com colagens de imitações estilísticas; e) a retomada da frontalidade da cena, a fim de assegurar a descontinuidade entre imagem e observador, provocando uma interrupção da percepção. A partir destes princípios relativos à cenografia, buscarei mostrar como as encenações de tragédias gregas contemporâneas dialogam com as teorias pós-modernas.

\section{Algumas encenações contemporâneas}

A partir das décadas de 1980 e 1990, observa-se um crescente movimento de encenação dos textos antigos, Nestes espetáculos, nota-se uma diversidade de propostas espaciais, seja na caixa cênica, seja fora do espaço tradicional, em espaços alternativos, seja ainda na reconstrução do espaço teatral. No interior destas experiências espaciais, a cenografia aponta para uma série de questões relativas ao fazer artístico da atualidade: a participação do espectador, a identidade cultural, a atualização dos temas gregos em função das condições culturais da sociedade brasileira, as formas de organização do espaço, a reescritura e adaptação de temas trágicos, as materialidades, entre outros.

No que diz respeito aos elementos cenográficos, em termos de procedimentos poéticos, nota-se, em primeiro lugar, a presença dos conceitos de citação e de comentário. Exemplar neste aspecto são as encenações de Antunes Filho.

Em Fragmentos troianos (1999), por exemplo, um dos elementos fundamentais da cenografia é o telão pintado. Este telão não somente constitui uma citação à série Lilith, do pintor alemão Anselm Kiefer, como 
também aparece como um comentário sobre a própria tradição cenográfica, na medida em que o painel pintado aparece também como um signo de uma idéia de teatro já superado, como um signo do passado. Ao mesmo tempo, a presença da pintura lembra também o gesto moderno de re-inserção da pintura na cena. A montagem de Antunes Filho traz de volta a pintura pela citação, assim, não é a pintura que se reinsere no espaço do teatro, mas a sua reprodução. A imagem passa assim a jogar com seu próprio sentido, ela é citação, pastiche, ela recusa a si mesma, num procedimento típico da poética pós-moderna. Ao mesmo tempo, esta imagem pintada contém diversos temas relacionados à tragédia: o conflito entre deuses e homens, a compreensão da tragédia enquanto fenômeno político, a ambigüidade da imagem, apontando para o fator trans-histórico do trágico. Além disso, toda a plasticidade do espetáculo é fundada na justaposição de imagens, o que implica a fusão de diversas referências culturais, enquanto tendência característica das poéticas pós-modernas.

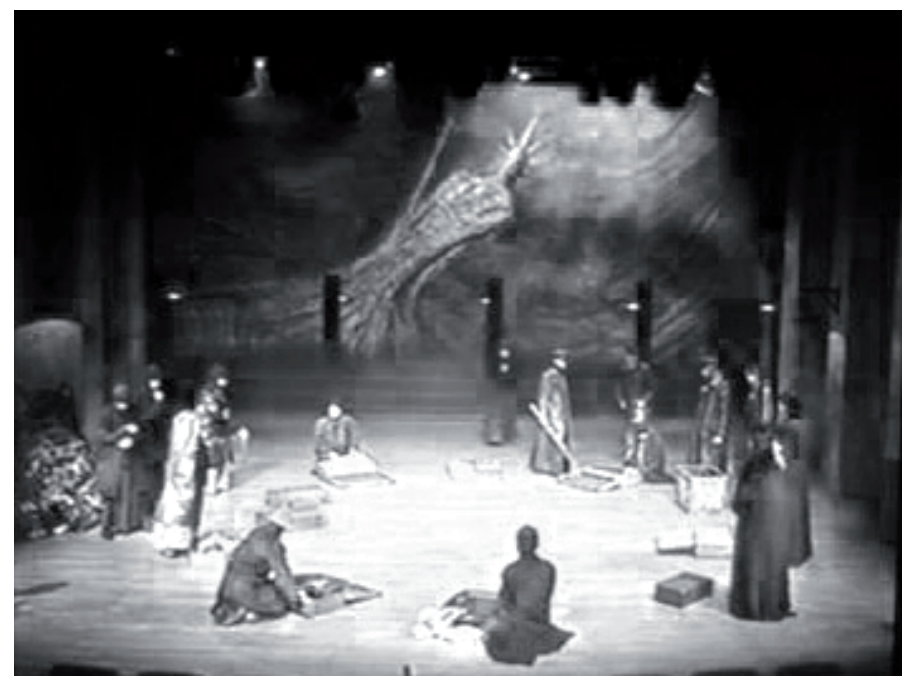

Fragmentos troianos. Foto realizada a partir do vídeo do espetáculo.

Em Medéia (2001), Antunes Filho recorre aos mesmos processos de citação e de justaposição, sendo que agora o objeto de citação é o próprio espaço cênico, pois a cenografia do espetáculo faz referência a três matrizes espaciais: o Teatro Nô japonês, presente nos elementos cênicos e no próprio estilo minimalista; o Teatro Grego, que se faz presente a partir da dinâmica da porta central e do eixo vertical da cena; e, por fim, a Contemporaneidade, por intermédio, sobretudo, de alguns objetos cênicos, como serras elétricas, plásticos, trajes com referências à atualidade, entre outros. O espaço 


\section{Urdimento}

trágico é criado na tensão entre essas três referências espaciais. Quer dizer, esta justaposição pode evocar uma incompatibilidade de ordem trágica, incompatibilidade esta que se constrói no jogo de oposições e de antagonismos, de identidade e distância. Ao confrontar estes espaços Medéia nos lança no seio de um conflito radical, mais precisamente, Antunes Filho aponta para uma cisão radical instauradora da historicidade do homem ocidental, cujas marcas principais são dadas pelo conflito entre natureza e civilização, pela separação entre o eu e a psique grupal, pela superação da sociedade matriarcal pela patriarcal, pela abordagem racional do mundo em confronto com a abordagem mítica, pela atitude agressora e desmedida em relação ao meio-ambiente. Deste modo, a cisão trágica, original é recuperada pela justaposição espacial presente na cenografia do espetáculo. Neste sentido, é nitidamente perceptível a continuidade das preocupações éticas de Antunes Filho, presentes em Fragmentos troianos: a crítica do modo de ação destrutiva do homem, a partir da razão instrumental, a qual leva a uma destruição da natureza.

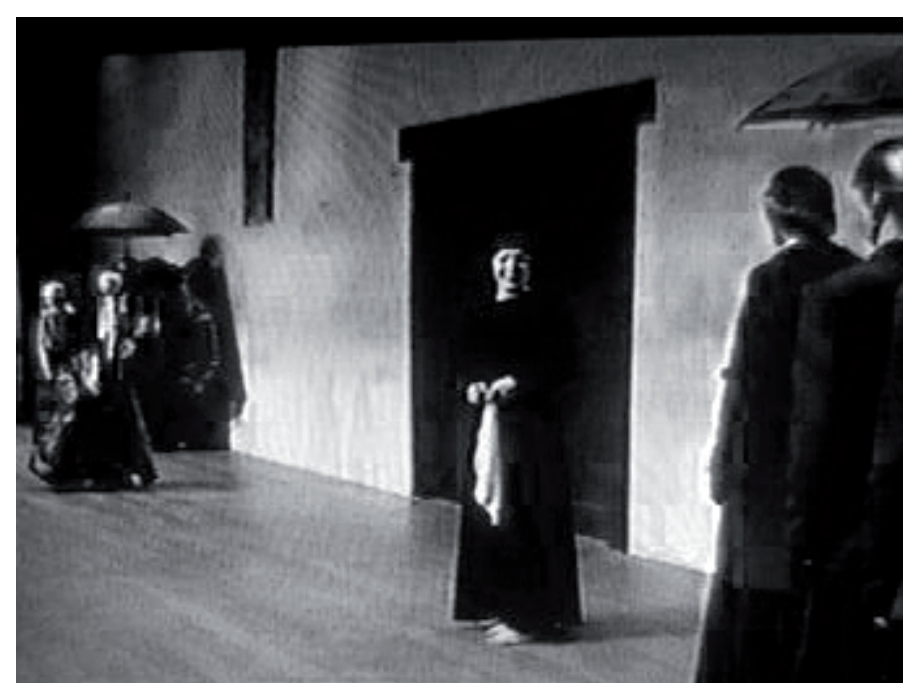

Medéia. Foto realizada a partir do video do espetáculo.

Já em Antígona (2004), a cenografia parece dialogar com outros dois procedimentos poéticos: a auto-referência, a qual se desdobra na idéia da metalinguagem, do teatro dentro do teatro, e a justaposição de elementos incompatíveis, como é o caso da união do espaço interior (um museu ou uma galeria de arte) com o exterior (um cemitério vertical), passado e presente, vida e morte, num procedimento que instaura a ambigüidade espacial. A cenografia de J. C. Serroni parece dialogar com as teorias de Michel Foucault 
acerca do espaço pós-moderno, mais precisamente, das heterotopias, visto que a cenografia parece reunir três heterotopias: o cemitério, o museu e o teatro. Neste jogo de ambigüidades dá-se uma acentuação na relação perceptiva entre o espectador e o objeto, enquanto elemento característico da cenografia pós-moderna.

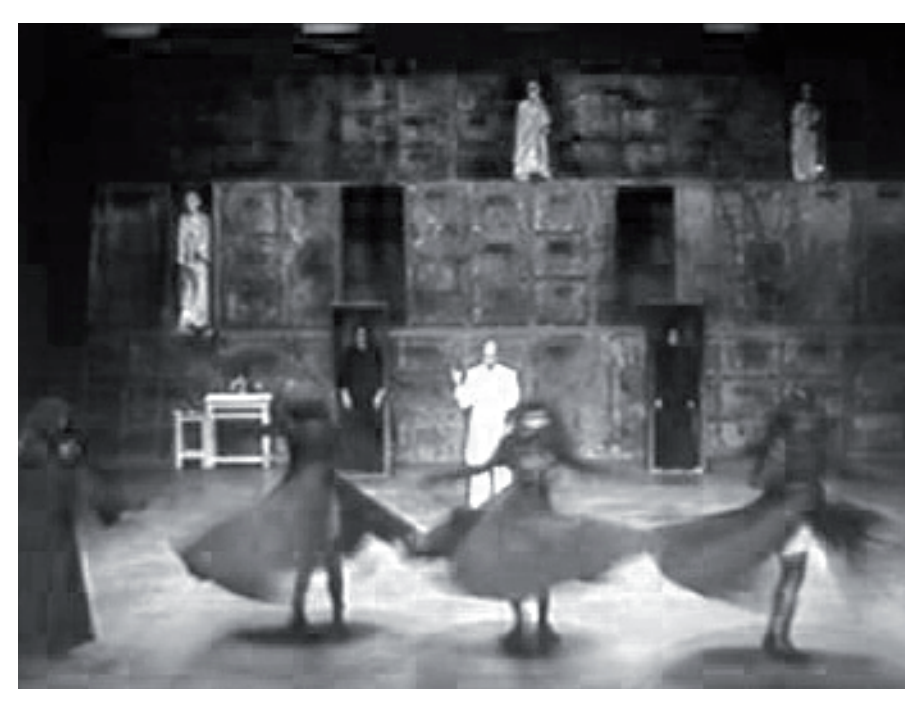

Antígona. Foto realizada a partir do vídeo do espetáculo.

A citação de um espaço cênico também está presente em Medéia (2003), do Teatro do Pequeno Gesto, com direção de Antonio Guedes e cenografia de Doris Rollemberg, onde os criadores trabalharam com a idéia de uma referência ao espaço grego. Mas, além da citação, este espetáculo parece conter um comentário crítico e irônico a respeito da própria operação de encenar o texto antigo. As formas circulares e a possibilidade de rotação do dispositivo cenográfico tendem a reforçar o elemento temporal e, conseqüentemente, o elemento épico da encenação. Desta forma, a cenografia propicia a intensificação do olhar histórico sobre a tragédia, quer dizer, um olhar crítico acerca da própria idéia de teatralidade, tal como esta aparece nos textos fundadores do teatro ocidental.

Outro elemento relevante na poética teatral pós-moderna é o próprio espaço. De um lado, o lugar teatral tenderá a ser cada vez mais diversificado, de outro, todo o ambiente em torno ao espetáculo será significativo para a leitura da obra e, de outro, o próprio edifício teatral, o suporte da obra, passará a ser elemento fundamental na construção dos signos cênicos.

Dezembro 2008 - №11 Tragédia grega e cenografica: a encenação dos textos trágicos... Gilson Motta. 


\section{Urdimento}

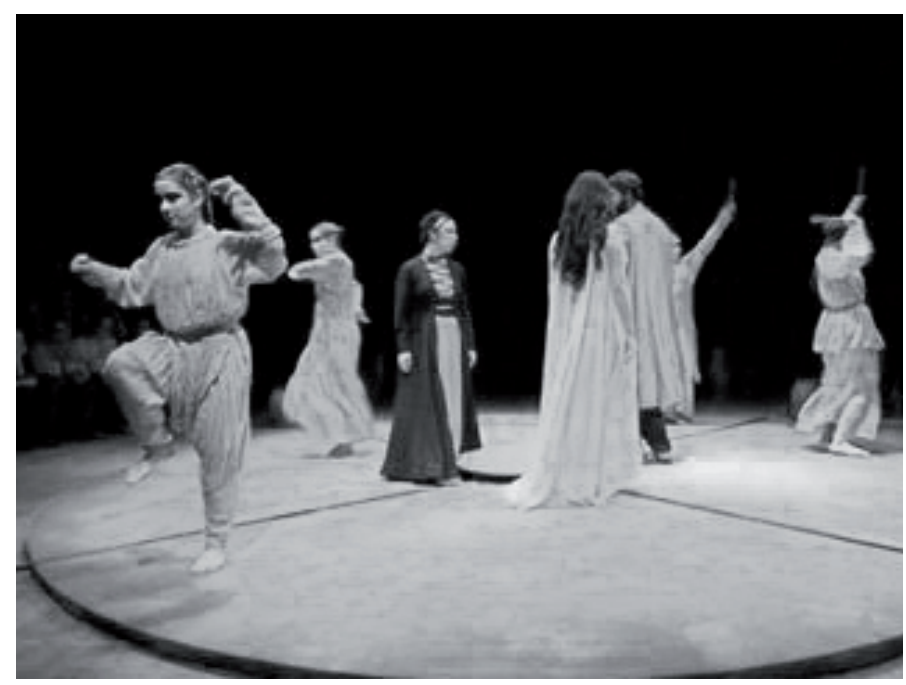

Medéia, Teatro do Pequeno Gesto. Foto de Luiz Henrique Sá e Jorge Etecheber.

Esta diversidade aparece, por exemplo, na profusão de espaços alternativos onde são realizadas as encenações de tragédias gregas. As fenícias, direção de Caco Coelho, foi realizada nos jardins do Museu da República, antigo Palácio do Catete, sede do Poder Executivo até 1960, no Rio de Janeiro. Pelo fato de esta montagem inserir elementos da linguagem circense, podemos especular sobre a possibilidade de uma contraposição simbólica e irônica entre o espaço destinado à elite, ao poder e ao exercício da razão política e o espaço destinado à fantasia, à irracionalidade, à poesia e às camadas populares. $\mathrm{O}$ pós-modernismo aproxima estes espaços. Um outro espetáculo de interesse no sentido em que joga com a diferença da recepção em função do espaço, é Electra, direção de Antonio Pedro. Este espetáculo foi criado e apresentado no Morro da Mangueira, no Rio de Janeiro, mas foi também exibido no Teatro Municipal desta mesma cidade. Assim, As fenícias e Electra apontam não somente para a integração de elementos da cultura popular ou de massa à cultura erudita, como revelam também que este nível de integração e de confronto se opera no nível espacial.

No que diz respeito à valorização do edifício teatral enquanto signo cênico, dignos de nota são os espetáculos As troianas, direção de Luís Furnaleto e o espetáculo Medéia, com direção de Bia Lessa, pois em ambos, a poética cênica é construída a partir de um edifício teatral em escombros ou ruínas. As troianas foi apresentado pelos alunos da Casa de Artes de Laranjeiras nos escombros do Teatro Casa Grande, no Rio de Janeiro, em 1998, um ano após o incêndio do teatro. Este contexto de destruição de uma importante casa de espetáculo parece ter servido de metáfora para se falar sobre a destruição, a guerra e, possivelmente, sobre a morte e o renascimento da tragédia grega. 


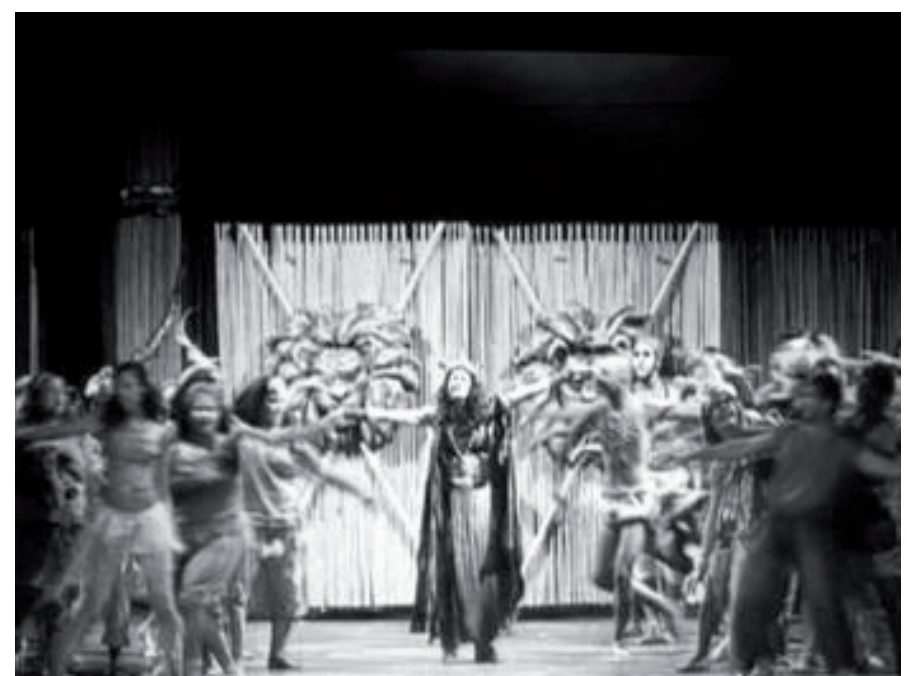

Electra na Mangueira. Foto realizada a partir do vídeo do espetáculo.

Apresentado no ano de 2004 no Teatro Dulcina, no Rio de Janeiro, Medéia, de Bia Lessa refaz o mesmo percurso, aproveitando-se das ruínas do teatro para construir a encenação. A diretora e o cenógrafo Gringo Cardia se apropriaram de um espaço tradicional da cidade do Rio de Janeiro que se encontrava em reforma, e criaram um espetáculo de grande impacto visual. No espetáculo, a separação entre o público e a cena se desfaz, a ação cênica faz explodir o espaço, estendendo os limites da cena, a própria arquitetura do teatro é aproveitada como signo cênico. A montagem de Bia Lessa nos remete a elementos essenciais da estética contemporânea, como a busca da integração entre o espaço da obra e o espaço do público, a apropriação do espaço histórico como forma de construção de um discurso poético, a presença da metalinguagem a partir da própria utilização da arquitetura teatral como tema cenográfico. Deste modo, a encenação trabalha com diversas zonas de limites: entre edifício teatral e cenografia, construção e destruição, passado e atualidade, permanência e desaparecimento.

Uma outra tendência que se mostra é a da busca da atualização por intermédio da presença de recursos tecnológicos. Um recurso como o vídeo, por exemplo, possibilita um discurso crítico acerca da mídia, assim como um discurso crítico acerca da política internacional. É o que se dá no espetáculo Antígona, do grupo Os Satyros, de São Paulo, espetáculo encenado em 2002. Em Antígona, o personagem Creonte aparece diversas vezes sob a forma de projeções de vídeo, além disso, sua voz também é registrada em áudio. O efeito resulta bastante eficaz, propiciando correlações entre o universo do texto e uma sociedade altamente policiada. Além disso, de modo paradoxal, o próprio poder - ou a imagem do poder - se torna mais familiar, na medida em que se revela distante, como uma transmissão de TV. Daí a associação entre o universo da peça e o da era George Bush.

Dezembro 2008 - № 11 Tragédia grega e cenografica: a encenação dos textos trágicos... Gilson Motta. 


\section{Urdimento}

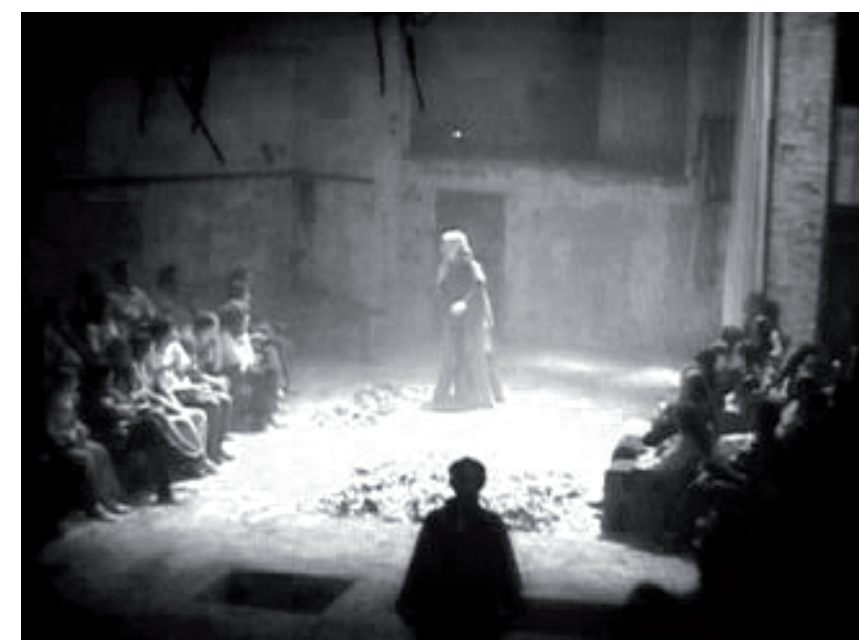

Medéia. Foto realizada a partir do vídeo do espetáculo.

O mesmo jogo com os meios de comunicação está presente no espetáculo Édipo Rei, direção de Diego Molina Mendes, realizado em 2007. Neste espetáculo todas as cenas se desenvolvem a partir de uma referência irônica a um programa de rádio ou televisão. É assim que a abertura do espetáculo se faz ao som da Voz do Brasil, com o personagem Édipo usando da palavra. É assim também que muitas cenas são tratadas como programas jornalísticos. A cenografia é um elemento fundamental para esta construção na medida em que nela são utilizados módulos que se deslocam e se recompõem, propiciando a criação de uma multiplicidade de espaços. Desta forma, o espetáculo possui um tratamento marcado pela ironia e pela distância, a qual é ressaltada pela referência à mídia.

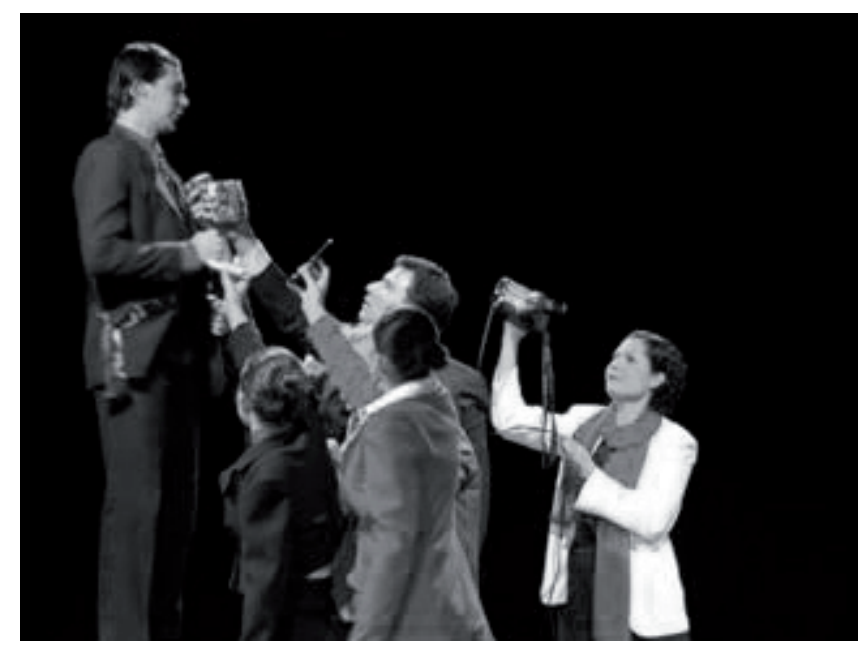

Édipo Rei. Foto de Renato Marques.

Tragédia grega e cenografica: a encenação dos textos trágicos... Gilson Motta.

Dezembro 2008 - № 11 


\section{Conclusão}

A partir de uma forma teatral específica, no caso, a tragédia grega, é possível se formar um panorama dos recursos técnicos e estéticos utilizados na cenografia brasileira no contexto do pós-modernismo. Neste sentido, a pesquisa aponta para a presença de elementos como a citação, a paródia, a ironia, a auto-referência, a justaposição, a metalinguagem, a mistura de estilos, a interação com o espectador, a abertura dos signos, a busca de outras formas de organização do espaço cênico, a utilização de recursos tecnológicos de criação da imagem, como o vídeo, a fotografia, projeções, entre outros.

\section{Referências bibliográficas}

ARONSON, Arnold. Cenografia pós-moderna. In: Cadernos de Teatro, nº 130. Rio de Janeiro: O Tablado, julho a setembro de 1992.

COELHO, Teixeira. Um teatro, uma dança pós-modernos. In: Moderno Pós Moderno: modos e versões. São Paulo: Iluminuras, 2005.

CONNOR, Steven. Performance pós-moderna. In: Cultura pós-moderna. Introdução às Teorias do Contemporâneo. São Paulo: Edições Loyola, 1996.

FOLEN, Helen. Modern Performance and Adaptation of Greek Tragedy. Washington, DC, 1998. American Philological Association. Presidential Address. Disponível em: <http://www.apaclassics.org/Publications/ PresTalks/FOLEY98.html>.

FOUCAULT, Michel. Estética: Literatura e pintura, música e cinema. Organização e seleção de textos de Manoel Barros da Motta. Rio de Janeiro: Forense Universitária, 2006.

HALL, Edith. Why Greek Tragedy in the Late Twentieth Century?. In: Dionysus Since 69: Greek Tragedy at the Dawn of the Third Millennium, Oxford: Oxford University Press, 2004.

LEGANGNEUX, Patrícia. Les tragédies grecques sur la scène moderne. Une utopie théâtrale. Louvain: Presses Universitaires Septentrion, 2004. 